\title{
Image analysis, methanogenic activity measurements, and molecular biological techniques to monitor granular sludge from an EGSB reactor fed with oleic acid
}

\author{
M.A. Pereira ${ }^{\star, \star \star}$, K. Roest ${ }^{\star \star}$, A.J.M. Stams ${ }^{\star \star}$, A.D.L. Akkermans ${ }^{\star \star}$, A.L. Amaral ${ }^{\star}$, M.-N. Pons ${ }^{\star \star *}$, \\ E.C.Ferreira*, M. Mota* and M.M. Alves* \\ * Centro de Engenharia Biológica, Universidade do Minho, 4710-057 Braga, Portugal \\ (E-mail: Madalena.alves@deb.uminho.pt) \\ ** Laboratory of Microbiology, Wageningen University, Hesselink van Suchtelenweg 4, NL-6703 CT \\ Wageningen, The Netherlands \\ *** Laboratoire des Sciences du Génie Chimique, CNRS-ENSIC-INPL, BP 451, F-54001 Nancy cedex, \\ France
}

\begin{abstract}
Morphological changes in anaerobic granular sludge fed with increasing loads of oleic acid were quantified by image analysis. The combination of this technique with data on the accumulation of adsorbed long chain fatty acid and with the molecular characterization of microbial community gave insight into the mechanisms of sludge disintegration, flotation and washout. It was found that the bacterial domain was more affected than the archaeal domain during this process. However, no acetoclastic activity and only a residual hydrogenotrophic activity were detected in the sludge at the end of the operation.

Keywords EGSB reactor; granular sludge; image analysis; long chain fatty acids; methanogenic activity; molecular techniques
\end{abstract}

\section{Introduction}

The use of 16S rDNA-based methods employing Denaturing Gradient Gel Electrophoresis (DGGE) (Muyzer and Smalla, 1998), molecular cloning and sequencing (Godon et al., 1997; Wu et al., 2001) can give insight into the microbial composition and diversity in complex communities, such as granular sludge or biofilms. Furthermore, when combined with morphological, and/or physiological monitoring techniques, they can provide important information to improve the understanding on the role and dynamics of these communities and their effect on reactor performance (Verstraete et al., 1996; Oude Elferink et al., 1998; Santegoeds et al., 1999). In anaerobic treatment of effluents with high lipid content, the application of sludge bed reactors is problematic because, besides the acute toxicity towards the acetogenic and methanogenic bacteria, long chain fatty acids (LCFA) resulting from lipids hydrolysis adsorb onto the biomass and provoke sludge flotation and subsequent washout. Granular sludge disintegrates and becomes encapsulated by a whitish, light and gelatinous mass. From a thermodynamic viewpoint, disintegration of granules is predictable because at neutral $\mathrm{pH}$, LCFA act as surfactants, lowering the surface tension, and hindering the aggregation of hydrophobic bacteria, like most acetogens (LCFA-degraders) (Hwu et al., 1997).

The aim of the present work was to monitor the granular sludge from an EGSB reactor fed with increasing loads of oleic acid, using an integrated approach combining image analysis, methanogenic activity measurements and molecular biological techniques to quantify changes in the granular sludge at morphological, physiological and microbial levels. Oleic acid was chosen as a model because it is generally, one of the more abundant LCFA in wastewaters as well as one of the more toxic. 


\section{Materials and methods}

A 101 EGSB reactor inoculated with 1.61 of granular sludge (20.2 g VSS/l) obtained from an UASB treating brewery effluent located in Oporto, was operated with increasing oleate concentrations between 2 and $8 \mathrm{~g} \mathrm{COD} / 1$ at a constant hydraulic retention time of 1 day. The operation of this reactor is described by Pereira et al. (2002) and Table 1 summarises the steady-state values of the operating conditions and performance data for each period. During the first 70 days the feed was composed of skim milk (50\% COD) and oleic acid (50\% COD). From day 70 onwards, the carbon source was exclusively composed of oleic acid. Macro- and micronutrients with a composition described elsewhere (Alves et al., 2001) were added.

During reactor operation the biomass was segregated into two layers, located at the bottom (heavy sludge) and at the top (floating sludge) of the reactor. On days 70, 92, 119, 141, 162,191 and 219 samples from the bottom and top layers were collected and characterized in terms of amount of adsorbed substrate and the corresponding potential maximum degradation rate measured in batch experiments. Image analysis was applied to the same samples in order to quantify the size of the aggregates and the number and total length of free filamentous bacterial forms. The biomass samples collected at the end of each applied oleate loading rate (days $70,119,162,219)$ were also analyzed by molecular techniques in order to monitor changes in microbial diversity along the operation.

\section{Batch experiments}

All the sludge samples collected from the reactor were washed and centrifuged (4000 rpm, $10 \mathrm{~min}$ ) twice with anaerobic basal medium and were incubated in batch vials of $25 \mathrm{ml}$ at $37^{\circ} \mathrm{C}, 150 \mathrm{rpm}$ under strict anaerobic conditions, without any added substrate. The methane production due to the degradation of the adsorbed substrate was followed by measuring the pressure developed in each vial, using a hand-held pressure transducer capable of measuring a pressure variation of two bar ( 0 to $\pm 202.6 \mathrm{kPa})$ over an output range of -200 to $+200 \mathrm{mv}$ and a minimum detectable variation of 0.005 bar corresponding to $0.05 \mathrm{ml}$ biogas in $10 \mathrm{ml}$ headspace (Colleran et al., 1992). The anaerobic basal medium used in all the batch experiments was composed of cysteine- $\mathrm{HCl}(0.5 \mathrm{~g} / \mathrm{l})$ and sodium bicarbonate $(3 \mathrm{~g} / \mathrm{l})$, the $\mathrm{pH}$ was adjusted to 7.0-7.2 and was prepared under strict anaerobic conditions. No calcium or trace-nutrients were added. The initial maximum methane production rate and the maximum values achieved (indirect measure of the amount of adsorbed substrate) were determined for each vial. All the batch experiments were performed in triplicate assays. Methanogenic activity tests were also performed using this technique.

\section{Image analysis}

Image acquisition for the quantification of free filamentous bacteria was accomplished through the visualization on a Diaphot 300 Nikon microscope (Nikon Corporation, Tokyo) with a $100 \times$ magnification. Images for the quantification of morphological parameters in the aggregates were acquired in an Olympus SZ40 stereomicroscope with a $15 \times$ magnification.

Table 1 Steady-state operating conditions and performance (mean $\pm 95 \%$ confidence intervals)

\begin{tabular}{lcccc}
\hline Period & $\begin{array}{c}\text { Time } \\
\text { (days) }\end{array}$ & $\begin{array}{c}\text { Influent COD } \\
(\mathbf{g} / \mathbf{1})\end{array}$ & $\begin{array}{c}\text { COD removal } \\
\text { efficiency (\%) }\end{array}$ & $\begin{array}{c}\text { Methane production } \\
\left(\mathbf{I C H}_{\mathbf{4}} / \mathbf{d a y}^{\mathbf{d}}\right)\end{array}$ \\
\hline 1 & $0-70$ & $3.8 \pm 0.3$ & $96.5 \pm 0.6$ & $10.6 \pm 1.0$ \\
2 & $70-119$ & $3.8 \pm 0.3$ & $83.4 \pm 4.8$ & $2.3 \pm 0.5$ \\
3 & $119-162$ & $6.2 \pm 0.7$ & $74.2 \pm 3.8$ & $1.6 \pm 0.2$ \\
4 & $162-219$ & $8.2 \pm 0.5$ & $68.8 \pm 3.4$ & $1.5 \pm 0.2$ \\
\hline
\end{tabular}


Images were digitised with a CCD AVC D5CE camera (Sony, Tokyo) and a DT 3155 frame grabber (Data Translation, Marlboro, MA, USA), with a $768 \times 576$ pixel size and 256 grey levels using the ImagePro Plus (Media Cybernetics, Silver Spring, MD, USA) software package. Morphological parameters were determined by means of two programs developed in Matlab 5.3 (The Mathworks, USA):

Filaments program. The number of filaments and the average filament length were determined by this program. First the original image was enhanced by means of a Mexican-hat filter (Russ, 1995), followed by a background homogenisation, Wiener filtering and histogram equalization. Subsequently, a defined threshold binarised the image. In order to identify the filaments skeletonisation and a 10 pixels length end-point removal was performed.

Floc program. The background from the original image was subtracted and then a previously defined threshold binarised the image. In the binarised image only the objects larger than $5 \times 5$ pixels were treated, discarding the debris present in the image. The particle size was evaluated by its equivalent diameter (Deq), calculated from its projected area (A) and by its minimum Feret diameter (the minimum distance between parallel tangents touching opposite sides of an object). The particle morphology was assessed by its roundness (Russ, 1995), defined as the ratio of the particle projected area to the area of the disk with the same convex perimeter (i.e. the perimeter of the smallest convex object that fits the object's boundaries).

\section{Microbial community analysis}

Total DNA was extracted as described by Harmsen et al. (1995) and the 16S rRNA-genes were amplified by Polymerase Chain Reaction (PCR) using a Taq DNA polymerase kit (Life Technologies, Gaithersburg, MD.). Complete bacterial 16S rDNA was selectively amplified for cloning and sequencing using 7-f (5'-AGAGTTTGAT(C/T)(A/C)TGGCTCAG-3') and 1510-r (5'-ACGG(C/T)TACCTTGTTACGACTT-3') primers (Lane, 1991). For DGGE a specific region of eubacteria 16S rDNA (V6-V8 region) was amplified using 968-GC-f (5'-CGCCCGGGGCGCGCCCCGGGCGGGGCGGGGGCACGGGGGGAACGCGAGAACCTTAC-3') and 1401-r (5'-CGGTGTGTACAAGACCC-3') primers (Nübel et al., 1996). For archaea, primers A109-f (5'-AC(G/T)GCTCAGTAACAGTAACACGT-3') (Grosskopf et al., 1998) and 1510-r were used for complete 16S rDNA amplification and A109(T)-f (original Grosskopf et al., 1998, third nucleotide changed into T only, Hans G.H.J. Heilig, personal communication) and 515-GC-r (5'-CGCCCGGGGCGCGCCCCGGGCGGGGCGGGGGCACGGGCTGCTGGCAC-3') (Lane, 1991) for V2-V4 region amplification for DGGE use. All primers were purchased from MWG-Biotech (Ebersberg, Germany).

DGGE analysis of the amplicons was done as described by Zoetendal et al. (2001). Denaturant gradients from 35 to $50 \%$ for bacterial amplicon separation and from 30 to $45 \%$ for the archaeal ones, were used. DGGE gels were scanned at 400 dpi and the DGGE profiles compared using the Molecular Analyst 1.12 software package (BioRad, Hercules, CA, USA). Similarity indices of the compared profiles were calculated from the densitometric curves of the scanned DGGE profiles by using the Pearson product-moment correlation coefficient (Häne et al., 1993). Community shifts were described as changes in the DGGE profiles of the partial 16S rDNA amplicons.

Cloning and sequencing with the Sp6 primer (5'-GATTTAGGTGACACTATAG-3') (MWG-Biotech, Ebersberg, Germany), was done as described by Heilig et al. (2002). Similarity search of the partial $16 \mathrm{~S}$ rDNA sequences derived from the sludge clones was 
performed using the NCBI sequence search service available from the internet (http//www.ncbi.nlm.nih.gov/blast/).

\section{Results and discussion}

Figure 1 summarises the results obtained in the batch experiments. The granular sludge present in the top layer exhibited higher amounts of absorbed substrate attaining a maximum value of $997 \pm 109 \mathrm{mg} \mathrm{COD}-\mathrm{CH}_{4} / \mathrm{gVSS}$ on day 162 , when oleate was fed at $6 \mathrm{~kg}$ $\mathrm{COD} / \mathrm{m}^{3}$.day. Methane production rate from the absorbed substrate was also maximal under these conditions ( $200 \pm 6 \mathrm{mg} \mathrm{COD}-\mathrm{CH}_{4} / \mathrm{gVSS}$.day).

For the oleate organic load of $8 \mathrm{kgCOD} / \mathrm{m}^{3}$.day, a clear inhibition of the adsorbed substrate degradation was found as a lag-phase of $300 \mathrm{~h}$ preceded the initial methane production (Pereira et al., 2002). A clear decrease was observed in both the amount of adsorbed substrate effectively degraded (100 $\pm 11 \mathrm{mg}$ COD- $\left.\mathrm{CH}_{4} / \mathrm{gVSS}\right)$ and the corresponding methane formation rate $\left(11 \pm 3 \mathrm{mg}\right.$ COD- $\mathrm{CH}_{4} / \mathrm{gVSS}$.day) in batch assays. The excessive accumulation of non-degraded substrate adsorbed onto the biomass can hinder the transfer of gaseous products, and thus cause a delay in the initial methane production as well as a reduction of the methane production rate. The same effect can, in part, explain the significant reduction in the methanogenic activity measured in the granular inoculum and in the final sludge. The sludge present at the end of the operation exhibited only a low hydrogenotrophic activity, which was less than $5 \%$ of the value exhibited by the granular inoculum and no detectable activity on the other substrates (Table 2). It should also be noted that, if the acetoclastic activity is rate limiting, the measurement of the methanogenic activity in the presence of propionate, butyrate and ethanol, indirect methanogenic substrates, can be underestimated.

Image analysis provided information about the morphology and aggregation status of the granular sludge. Along the trial period, the fraction of fine aggregates (with a minimal Feret diameter smaller than $1 \mathrm{~mm}$ ) increased steadily from $27 \%$ to $76 \%$, in terms of

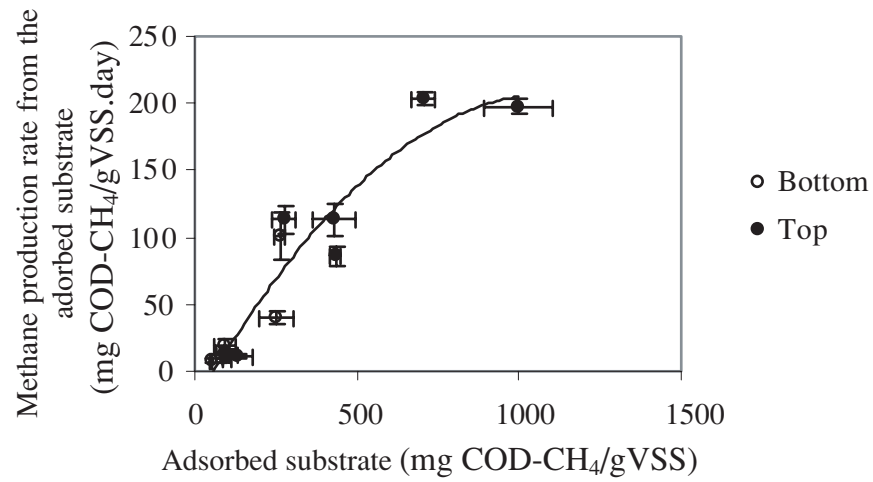

Figure 1 Effect of the amount of adsorbed substrate on the methane production rate

Table 2 Methanogenic activity for the granular sludge (mean \pm standard deviation of triplicates)

\begin{tabular}{ccc}
\hline & Granular inoculum & Final sludge (end of operation) \\
\hline Methanogenic activity in presence of: & $\left(\mathrm{mlCH}_{4(\mathrm{STP})} / \mathrm{gVSS}\right.$.day) & \\
Acetate & $327 \pm 11$ & (n.d.) \\
Propionate & $160 \pm 10$ & (n.d.) \\
Butyrate & (n.d.) & (n.d.) \\
Ethanol & $514 \pm 94$ & (n.d.) \\
$\mathrm{H}_{2} / \mathrm{CO}_{2}$ & $597 \pm 16$ & $27.8 \pm 1.1$ \\
\hline
\end{tabular}


projected area, clearly indicating the occurence of granule disintegration. The morphology of the non-fine aggregates could be related to the adsorption of LCFA onto the sludge (Table 3). In the bottom sludge, the size of the non-fine aggregates increased with the amount of adsorbed substrate to a maximum value of about $250 \mathrm{mg} \mathrm{COD}-\mathrm{CH}_{4} / \mathrm{gVSS}$, corresponding to a diameter of $1.79 \mathrm{~mm}$. On the other hand, in the top sludge which in general exhibited a significantly higher amount of adsorbed substrate, a decreasing trend of the size of the non-fine aggregates was observed with increasing amounts of adsorbed substrate. This suggests that when more LCFA was adsorbed, a migration of aggregates towards the top layer will occur with a simultaneous decrease in size, possibly due to disintegration.

The number of free filaments (per unit of VSS concentration) also increased with the amount of absorbed LCFA, suggesting that granular disintegration was simultaneous with a release of filamentous organisms to the medium (Amaral et al., 2001). Concerning the fine aggregates $(<1 \mathrm{~mm})$, it was observed that when their size increased in the range of $0.2-0.3 \mathrm{~mm}$ the degradation rate of the adsorbed LCFA decreased sharply from 434 to $13 \mathrm{mg} \mathrm{COD}-\mathrm{CH}_{4} / \mathrm{gVSS}$.day, possibly due to internal diffusion limitations of intermediates such as acetate and products such as methane. This result highlights the advantage of using suspended/dispersed biomass over aggregated biomass towards the methanization of LCFA, as reported before (Pereira et al., 2002).

Microbial community analysis seemed to be in accordance with the granular disintegration quantified by image analysis, as a clear shift in the bacterial consortium (usually located in the outer layer of granules) was observed with the increase in the toxicant fed to the reactor. This suggests a selective washout of acetogenic bacteria. The comparison of DGGE band-patterns revealed a decrease in the similarity indices between the bottom and top from 86.8, in the first operation period, to 56.7 in the last operation period (oleate load of $8 \mathrm{~kg} \mathrm{COD} / \mathrm{m}^{3}$.day) (Table 4 (I)). At the end of the operation (period 4), the similarity index between bottom sludge and the inoculum was 42.8 , whereas between the top sludge and the inoculum it was 17.3. This suggests that a higher shift in the community structure occurred in the top than in the bottom sludge. Furthermore, in the top sludge, the increase in the oleate loading rate from 6 to $8 \mathrm{~kg} \mathrm{COD} / \mathrm{m}^{3}$.day caused a large shift in the community structure (the similarity index between the top sludge at the end of period 3 and 4 was of only 14.9). This significant shift in the microbial structure of the top sludge could include the loss of microorganism particularly important in the methanisation of LCFA and thus explain the differences in the methane production capacity from the absorbed substrate exhibited by the sludge at the end of both periods, in the batch experiments.

The selective washout of acetogenic bacteria during the operation can also be related to the absence of methanogenic activity with propionate, butyrate and ethanol exhibited by the granular sludge at the end of operation (Table 1). For the archaeal consortium no significant shift in the granular community patterns was detected (Table 4 (II)), which can be

Table 3 Amount of adsorbed substrate and equivalent diameter of non-fine aggregates present in the bottom and top sludge (mean \pm standard deviation)

\begin{tabular}{lccc}
\hline \multicolumn{2}{c}{ Bottom sludge } & \multicolumn{2}{c}{ Top sludge } \\
$\begin{array}{l}\text { Adsorbed substrate } \\
\text { (mgCOD-CH4/gVSS) }\end{array}$ & $\begin{array}{c}\text { Non-fine average } \\
\text { equivalent diameter (mm) }\end{array}$ & $\begin{array}{l}\text { Adsorbed substrate } \\
\text { (mgCoD-CH4/gVss) }\end{array}$ & $\begin{array}{c}\text { Non-fine average } \\
\text { equivalent diameter (mm) }\end{array}$ \\
\hline $51.1 \pm 2.9$ & $1.36 \pm 0.08$ & $98.9 \pm 12.0$ & $1.67 \pm 0.20$ \\
$90.9 \pm 34$ & $1.48 \pm 0.04$ & $133.7 \pm 47.4$ & $1.70 \pm 0.17$ \\
$93.7 \pm 10.9$ & $1.53 \pm 0.07$ & $276.0 \pm 37.4$ & $1.63 \pm 0.04$ \\
$96.6 \pm 33.1$ & $1.51 \pm 0.05$ & $430.0 \pm 67.4$ & $1.58 \pm 0.05$ \\
$97.1 \pm 5.4$ & $1.46 \pm 0.08$ & $433.7 \pm 17.1$ & $1.53 \pm 0.03$ \\
$250.6 \pm 53.4$ & $1.79 \pm 0.07$ & $704.9 \pm 34.6$ & $1.64 \pm 0.04$ \\
$262.9 \pm 16.6$ & $1.65 \pm 0.03$ & $997.7 \pm 107.1$ & $1.47 \pm 0.04$ \\
\hline
\end{tabular}


Table 4 Similarity matrix calculated from: (I) bacterial DGGE profiles and (II) archaeal DGGE profiles of each sludge sample

\begin{tabular}{|c|c|c|c|c|c|c|c|c|c|}
\hline (I) & $\mathbf{G}$ & $b_{1}$ & $b_{2}$ & $b_{3}$ & $b_{4}$ & $t_{1}$ & $t_{2}$ & $t_{3}$ & $t_{4}$ \\
\hline G & 100 & & & & & & & & \\
\hline$b_{1}$ & 61.3 & 100 & & & & & & & \\
\hline$b_{2}$ & 75.8 & 77.1 & 100 & & & & & & \\
\hline$b_{3}$ & 56.1 & 67.2 & 77.4 & 100 & & & & & \\
\hline$b_{4}$ & 42.8 & 37.5 & 45.0 & 62.7 & 100 & & & & \\
\hline$t_{1}$ & 68.0 & $\underline{86.8}$ & 66.2 & 60.7 & 43.2 & 100 & & & \\
\hline$t_{2}$ & 82.9 & 71.4 & $\underline{84.9}$ & 72.0 & 37.9 & 71.1 & 100 & & \\
\hline$t_{3}$ & 80.3 & 59.1 & 74.2 & $\underline{60.3}$ & 35.1 & 62.6 & 86.6 & 100 & \\
\hline$t_{4}$ & 17.3 & 18.4 & 22.3 & 44.6 & $\underline{56.7}$ & 19.9 & 23.3 & 14.9 & 100 \\
\hline (II) & $\mathbf{G}$ & $B_{1}$ & $b_{2}$ & $b_{3}$ & $b_{4}$ & $t_{1}$ & $t_{2}$ & $t_{3}$ & t4 \\
\hline G & 100 & & & & & & & & \\
\hline$b_{1}$ & 97.6 & 100 & & & & & & & \\
\hline$b_{2}$ & 92.4 & 97.0 & 100 & & & & & & \\
\hline$b_{3}$ & 79.5 & 87.6 & 95.7 & 100 & & & & & \\
\hline$b_{4}$ & 72.0 & 78.7 & 88.7 & 93.5 & 100 & & & & \\
\hline$t_{1}$ & 95.9 & $\underline{97.7}$ & 93.3 & 83.5 & 74.4 & 100 & & & \\
\hline$t_{2}$ & 95.8 & 98.7 & $\underline{94.8}$ & 84.5 & 76.4 & 98.4 & 100 & & \\
\hline$t_{3}$ & 94.7 & 98.3 & $\overline{97.2}$ & $\underline{90.5}$ & 84.2 & 96.6 & 98.5 & 100 & \\
\hline$t_{4}$ & 75.2 & 81.4 & 89.8 & 93.6 & $\underline{98.9}$ & 77.9 & 79.6 & 86.7 & 100 \\
\hline
\end{tabular}

related to the more protected environment against the toxic effect and hydraulic shear stress offered to the methanogenic organisms (archaea domain) normally located in the inner core of the granules.

Figure 2 illustrates the molecular characterisation of the samples at the end of operation. The sequencing of the bacterial clones resulted mainly in matches with unknown and uncultured microorganisms. For the archaeal domain the cloned sequences were affiliated with the two main groups, the acetoclastic Methanosaeta and the hydrogenotrophic Methanobacterium. However, although exhibiting some hydrogenotrophic activity, no acetoclastic activity was detected in this sludge (Table 1). This suggests that the presence of this group of microorganisms became weaker during the oleate load operation. Phenomena such as the acute toxicity of oleate to this group of microorganisms (Alves et al., 2001) and substrate unavailability either due to diffusion limitations through the LCFA accumulation on the aggregates or due to the selective washout of acetogenic bacteria (responsible for the acetate production) could be responsible for this.

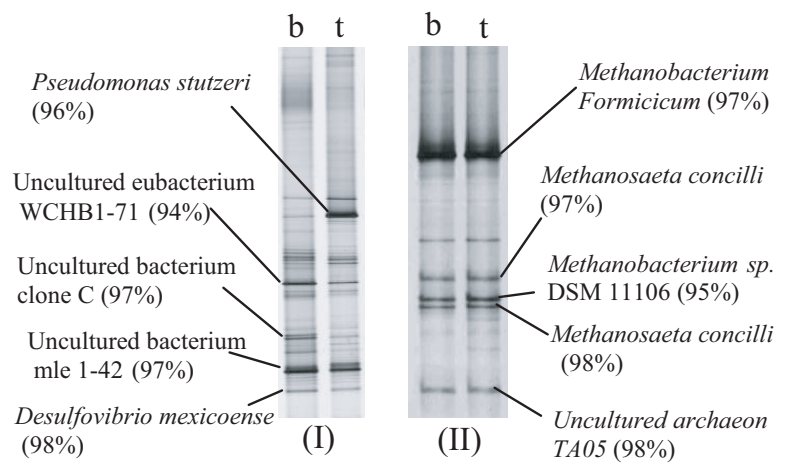

Figure 2 Molecular characterization of the granular sludge at end of operation: (I) bacterial domain, (II) 


\section{Conclusions}

Monitoring of granular sludge at microbial, morphological and physiological levels allowed the understanding of the mechanisms of sludge disintegration, flotation and washout in an EGSB reactor fed with increasing loads of oleic acid. Image analysis was a powerful tool that provided the quantification of morphological changes in the anaerobic granular sludge, evidencing the occurrence of sludge disintegration. The morphology of the aggregates could be related to the amount of adsorbed substrate and to the degradation rate of this substrate, in batch assays. When the amount of adsorbed LCFA increased, a migration of aggregates towards a top floating layer was observed with a simultaneous decrease in size. The molecular characterization of the microbial community indicated that the bacterial domain was most affected during the process of sludge disintegration, flotation and washout. The archaeal consortium remained less affected although no acetoclastic and only a residual hydrogenotrophic activity was detected at the end of the operation.

\section{Acknowledgements}

The authors wish to thank the Fundação Calouste Gulbenkian and the Fundação para a Ciência e Tecnologia (FCT) for the financial support given to Alcina Pereira for her stay in Wageningen and for her PhD grant, and FCT for the financial support given to António Luís Amaral for his PhD grant. The ICCTI (Portugal) and "Ambassade de France" in Portugal provided financial support for co-operation between the Braga and Nancy teams through the project $203 \mathrm{~B} 4$.

\section{References}

Alves, M.M., Mota Vieira, J.A., Álvares Pereira, R.M., Pereira, M.A., Novais, J.M. and Mota, M. (2001). Effects of lipids and oleic acid on biomass development in anaerobic fixed reactors. Part II: Oleic acid toxicity and biodegradability. Wat. Res., 35, 264-270.

Amaral, A.L., Pereira, M.A., Neves, L., da Mota, M., Pons, M.-N., Vivier, H., Mota, M., Alves, M.M. and Ferreira, E.C. (2001). Characterisation of anaerobic sludge from two EGSB reactors treating oleic acid: automatic detection of granules disintegration by image analysis. In: Proc. 9th World Congress on Anaerobic Digestion 2001 (van Velsen, A.F.M. and Verstraete, W.H., Eds), Part 1, pp. 89-94. Technologisch Instituut, Antwerpen.

Colleran, E., Concannon, F., Goldem, T., Geoghegan, F., Crumlish, B., Killilea, E., Henry, M. and Coates, J. (1992) Use of methanogenic activity tests to characterize anaerobic sludges, screen for anaerobic biodegradability and determine toxicity thresholds against individual anaerobic trophic groups and species. Wat. Sci. Tech., 25(7), 31-40.

Godon, J., Zumstein, E., Dabert, P., Habouzit, F. and Moletta, R. (1997). Molecular microbial diversity of an anaerobic digester as determined by small-subunit rDNA sequence analysis. Appl. Environ. Microbiol., 63, 2802-2813.

Grosskopf, R., Janssen, P.H. and Liesack, W. (1998). Diversity and structure of the methanogenic community in anoxic rice paddy soil microcosms as examined by cultivation and direct 16S rRNA gene sequence retrieval. Appl. Environ. Microbiol., 64, 960-969.

Häne, B.G., Jäger, K. and Drexler, H. (1993). The Pearson product-moment correlation coefficient is better suited for identification of DNA fingerprint profiles than band matching algorithms. Electrophoresis, 14, 967-972.

Harmsen, H.J.M., Kengen, H.M.P., Akkermans, A.D.L. and Stams, A.J.M. (1995). Phylogenetic analysis of two propionate-oxidizing bacteria in enrichments cultures. System. Appl. Microbiol., 18, 67-73.

Heilig, H.G.H.J., Zoetendal, E.G., Vaughan, E.E., Marteau, P., Akkermans, A.D.L. and de Vos, W.M. (2002). Molecular diversity of Lactobacillus spp. and other lactic acid bacteria in the human intestine as determined by specific amplification of $16 \mathrm{~S}$ ribosomal DNA. Appl. Environ. Microbiol., 68, 114-123.

Hwu, C.-S. (1997). Enhancing anaerobic treatment of wastewaters containing oleic acid. Ph.D. Thesis, Wageningen Agricultural University.

Lane, D.J. (1991). 16S/23S rRNA sequencing. In: Nucleic Acid Techniques in Bacterial Systematics (Stackebrandt, E.R. and Goodfellow, M., Eds.), pp. 115-175. John Wiley and Sons Ltd., Chichester, UK. 
Muyzer, G. and Smalla, K. (1998). Application of denaturing gradient gel electrophoresis (DGGE) and temperature gradient gel electrophoresis (TGGE) in microbial ecology. Antonie Leeuwenhoek, 73, $127-141$.

Nübel, U., Engelen, B., Felske, A., Snaidr, J., Wieshuber, A., Amann, R.I., Ludwig, W. and Backhaus, H. (1996). Sequence heterogeneities of genes encoding 16S rRNAs in Paenibacillus polymyxa detected by temperature gradient gel electrophoresis. J. Bacteriol., 178, 5636-5643.

Oude Elferink, S.J.W.H., van Lis, R., Heilig, H.G.H.J., Akkermans, A.D.L. and Stams, A.J.M. (1998). Detection and quantification of microorganisms in anaerobic bioreactors. Biodegradation, 9, 169-177.

Pereira, M.A., Pires, O.C., Mota, M. and Alves, M.M. (2002). Anaerobic degradation of oleic acid by suspended and granular sludge: identification of palmitic acid as a key intermediate. Wat. Sci.Tech., 45(10), 139-144.

Russ, J.C. (1995). The Image Processing Handbook, CRC Press, Boca Raton, Florida.

Santegoeds, C.M., Damgaard, L.R., Hesselink, G., Zopfi, J., Lens, P., Muyzer, G. and de Beer, D. (1999). Distribution of sulphate-reducing and methanogenic bacteria in anaerobic aggregates determined by microsensor and molecular analyses. Appl. Environ. Microbiol., 65, 4618-4629.

Verstraete, W., De Beer, D., Pena, M., Lettinga, G. and Lens, P. (1996). Anaerobic bioprocessing of waste. World J.Microbiol. Biotechnol., 12, 221-238.

Wu, J.-H., Liu, W.-T., Tseng, I.-C. and Cheng, S.-S. (2001). Characterization of microbial consortia in a terephthalate-degrading anaerobic granular sludge system. Microbiology, 147, 373-382.

Zoetendal, E.G., Akkermans, A.D.L., Akkermans-van Vliet, W.M., de Visser, J.A.G.M. and de Voss, W.M. (2001). The host genotype affects the bacterial community in the human gastrointestinal tract. Microbial Ecol. Health Dis., 13, 129-134. 